\title{
Entraves estruturais à segurança alimentar e nutricional a partir da oferta de alimentos no Brasil
}

\section{Structural barriers to food and nutrition security from food supply in Brazil}

Thomás Herr Zaterka ${ }^{1}$

No debate contemporâneo, a temática da Segurança Alimentar e Nutricional (SAN) procura agregar as distintas dimensões do problema social da má alimentação e suas complexas relações com o sistema econômico e com as instituições públicas e privadas. Trata-se de um conceito interdisciplinar em construção, um conceito normativo em disputa política e um conceito que se transforma junto do processo de complexificação das expressões epidemiológicas da má nutrição nas sociedades modernas. Uma possível abordagem interpretativa dos determinantes das condições nutricionais de uma população toma como ponto de partida os sistemas de instituições que conformam a estrutura econômica associada à oferta, como à produção e à distribuição, e associada à demanda, como à acessibilidade econômica e à capacidade de uso pelas comunidades ou indivíduos. Para as famílias, a estrutura de oferta deveria garantir alimentos em quantidade suficiente, diversificados e de boa qualidade nutricional e livres de contaminações, além de assegurar uma disponibilidade regular, tanto no curto como no longo prazo.

No Brasil, as políticas públicas pela SAN convergiram até 2014 para os problemas diagnosticados na esfera da demanda, principalmente para a garantia da acessibilidade econômica das famílias. Partia-se do correto diagnóstico de que a questão alimentar no país era primeiramente um problema de baixa renda, embasado nas estatísticas sobre a desigualdade e a pobreza no país e também nas cifras de produção agrícola que cresciam aceleradamente. Decorre, todavia, que ainda podem ser identificados graves entraves estruturais à boa qualidade do alimento, à regularidade da oferta e mesmo às quantidades efetivamente comercializadas no elo final da cadeia. No presente contexto de fragilização das instituições comprometidas com a dignidade alimentar no país, entende-se ser importante esclarecer a essencialidade das ações do Poder Público para a SAN também na esfera da oferta doméstica.

A comunicação parte, assim, da seguinte questão norteadora: persistem problemas estruturais de oferta doméstica para garantir o direito à alimentação adequada no Brasil? Para respondê-la, o estudo se subdivide em cinco panoramas quali-quantitativos, que abarcam diferentes elos do sistema de oferta: 1. O modelo de produção agropecuária; 2. O sistema de transportes de carga; 3. O sistema de abastecimento urbano; 4. A atividade da indústria processadora; e 5. A acessibilidade física da família rural e a produção de autoconsumo. Para cada segmento são elencados limitantes estruturais às seguintes categorias da oferta adequada de alimentos: a) Quantidade disponibilizada; b) Qualidade, no que tange o aspecto nutricional e a inocuidade; e c) Regularidade e sustentabilidade da oferta. Objetiva-se esclarecer a complexidade da questão alimentar no país, indicando a necessidade de um projeto de desenvolvimento que traga mudanças estruturais para a oferta adequada de alimentos. 
Palavras-chave: segurança alimentar e nutricional; desenvolvimento econômico; sistemas agroalimentares.

Keywords: food and nutrition security; economic development; agri-food systems.

1 Mestrando em Desenvolvimento Econômico pela Universidade Estadual de Campinas. 